\title{
EFECTO GASTROPROTECTOR Y ANTISECRETOR DE UN FITOFÁRMACO DE HOJAS DE MATICO (Piper aduncum)
}

\author{
Jorge Arroyo, 1,2, a, Pablo Bonilla ${ }^{3, a}$, Luis Moreno-Exebio ${ }^{4, a}$, Gerardo Ronceros ${ }^{1,5, b}$, Gloria Tomás ${ }^{6, c}$, \\ Juana Huamán ${ }^{6, \mathrm{c}}$, Ernesto Raez ${ }^{7, \mathrm{~b}}$, Mariano Quino $^{1,8, \mathrm{~b}}$, Javier Rodriguez-Calzado ${ }^{4, \mathrm{~d}}$
}

\section{RESUMEN}

Objetivos. Determinar el efecto gastroprotector y antisecretor del extracto etanólico de las hojas de matico (Piper aduncum) en modelos animales. Materiales y métodos. Para la evaluación del efecto gastroprotector se utilizó 220 ratones de la cepa Balb C57, los cuales fueron aleatorizados en 22 grupos de diez animales, a los cuales se les indujo la formación de úlceras gástricas con indometacina, la gastroprotección se determinó a través de tres aspectos: inflamación, número de bandas hemorrágicas y número de úlceras. Para evaluar el efecto antisecretor se utilizó 64 ratas albinas machos Holtzman, los cuales fueron aleatorizados en ocho grupos de ocho animales, un control y siete grupos de tratamiento con un nivel de dosis de los extractos y dos niveles de dosis en los fitofármacos; la antisecreción se realizó con el ensayo de ligazón pilórica. Resultados. Para la gastroprotección, los extractos de diclorometano, cloroformo, hexano y metanol, lograron una disminución de la inflamación de más del $66 \%(p<0,05)$; el extracto etanólico presenta una actividad de $100 \%$ para disminuir el número de bandas hemorrágicas $(p<0,05)$; el extracto clorofórmico presenta una actividad antiulcerosa de $75 \%(p<0,05)$. Respecto a la antisecreción, el fitofármaco en cápsulas conteniendo el extracto etanólico logró un $72 \%$ de reducción del volumen de la secreción gástrica $(p<0,01)$ y un incremento del $\mathrm{pH}$ en $104,3 \%(p<0,01)$. Conclusiones. En condiciones experimentales los extractos etanólico, sus fracciones y su fitofármaco son gastroprotectores en ratones y antisecretores en ratas.

Palabras clave: Matico; Plantas medicinales; Fitoterapia; Extractos vegetales (fuente: DeCS BIREME).

\section{GASTROPROTECTIVE AND ANTISECRETORY EFFECT OF A PHYTOCHEMICAL MADE FROM MATICO LEAVES (Piper aduncum)}

\begin{abstract}
Objectives. To determine the gastroprotective and antisecretory effect of ethanol extract from matico leaves (Piper aduncum) in animal models. Materials and methods. To evaluate the gastroprotective effect, 220 mice of the Balb C57 strain were used. They were randomized in 22 groups of ten animals each, in which the formation of gastric ulcers was induced with indomethacin. Gastroprotection was determined by evaluating three aspects: inflammation, number of hemorrhagic shocks and number of ulcers. To evaluate the antisecretory effect, 64 white male Holtzman rats were used, which were randomized in eight groups of eight animals, one control and seven groups of treatment with one extract dose level and two phytochemical dose levels. Antisecretion was obtained through the pylorus ligation. Results. Regarding gastroprotection, dichloromethane, chloroform, hexane and methanol extracts decreased inflammation to over $66 \%(p<0,05)$. The ethanolic extract shows $100 \%$ activity in reducing the number of hemorrhagic bands $(p<0,05)$. The chloroform extract shows antiulcer activity at $75 \%$ $(p<0,05)$. In terms of antisecretion, the phytochemical in capsules containing the ethanolic extract achieved $72 \%$ reduction of the gastric secretion volume $(p<0,01)$ and $104,3 \%(p<0,01) \mathrm{PH}$ increase. Conclusions. In experimental conditions, ethanolic extracts, their fractions and phytochemicals have a gastroprotective effect in mice and antisecretory effect in rats.
\end{abstract}

Key words: Matico; Plants, medicinal; Phytotherapy; Plant extracts (source: MeSH NLM).

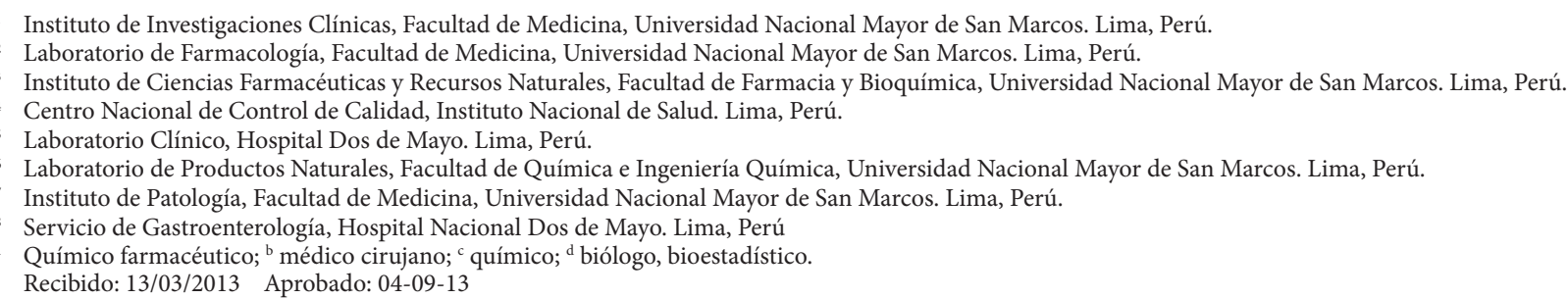

Citar como: Arroyo J, Bonilla P, Moreno-Exebio L, Ronceros G, Tomás G, Huamán J, et al. Efecto gastroprotector y antisecretor de un fitofármaco de hojas de matico (Piper aduncum). Rev Peru Med Exp Salud Publica. 2013;30(4):608-15. 


\section{INTRODUCCIÓN}

La úlcera péptica (UP) es una enfermedad heterogénea atribuible a una serie de factores que, de forma aislada o en combinación, actúan produciendo un desequilibrio entre los elementos agresivos y defensivos de la mucosa gastroduodenal que conlleva a la aparición de lesiones en el estómago y duodeno (1). Se ha descrito que el uso inadecuado de ácido acetilsalicílico (AAS) y de los antinflamatorios no esteroides (AINES) esta asociado con un incrementao en el número de las complicaciones de la úlcera péptica, entre las cuales se encuentran la hemorragia digestiva alta y la perforación de la mucosa gástrica o duodenal. Se ha descrito, en países del primer mundo, como EE. UU., que estas complicaciones tienen un considerable impacto económico, sobre todo en relación a la pérdida de productividad en el trabajo, estimándose estas pérdidas en 5,65 billones de dólares americanos por año. En los Países Bajos se calcula que el costo per cápita por caso de hemorragia, perforación, o una combinación de ambos es de 12 000, 19000 y 26000 euros, respectivamente (2). En el Perú, desde tiempos ancestrales, las hojas de diversas especies del género Piper se usan en infusión para tratar tanto malestares estomacales como úlceras estomacales ${ }^{(3)}$. En las comunidades asháninca, de Bajo Quimiriki y Yanesha usan el matico (Piper adumcun) para tratar una diversidad de enfermedades, incluyendo la cicatrización de heridas, las úlceras y el dolor estomacal ${ }^{(4,5)}$.

En la literatura biomédica, existen numerosos reportes que señalan la actividad antiulcerosa de varias especies del género Piper. Apechea et al. ${ }^{(6)}$ encontraron que la solución de flavonoides de Piper ossanum mostró un efecto antiulceroso similar al sucralfato. Asimismo, Luziatelli et al. (4) han señalado que los flavonoides (vitexina, isovitexin, rhamnopyranosylvitexin e isoembigenin) aislados de Piper carpunya (Carpundia, ccarpunya, jarpunya, baso sach), especie de amplia distribución en la Amazonía y en el valle del Marañón, tendrían efectos antimieloproliferativos (anti-MPO) y anti-Helicobacter pylori. Ellos postulan que estos flavonoides pueden ser responsables de la inhibición de la bomba $\mathrm{H}^{+}$y de la bomba $\mathrm{K}^{+}$ATPasa. Por su parte, Quílez et al. (7) aislaron fitosteroles y fitol de Piper carpunya señalando que ellos estarían involucrados en la actividad gastroprotectora de las especies del género Piper.

Existen fármacos estándares para el tratamiento de úlcera péptica y cáncer gástrico, con reconocidos efectos adversos y de acceso limitado debido a su costo ${ }^{\left({ }^{8}\right)}$. sin embargo, es necesario investigaciones que permitan incorporar productos naturales alternativos de bajo costo, que puedan ser una opción terapéutica en el tratamiento de las úlceras pépticas con la menor cantidad de efectos adversos. Para ese fin, es necesario promover investigaciones que busquen obtener un fitofármaco hecho sobre la base de materia prima vegetal, por ejemplo del extracto estabilizado de las hojas de alguna de las especies del genero Piper, que ya han probado alguna actividad gastroprotectora. Para ello es necesario investigaciones en modelos animales de experimentación, para generar sustratos científicos que posteriormente permitan el uso de estos fitofármacos en seres humanos. El objetivo de la presente investigación fue determinar el efecto gastroprotector $y$ antisecretor de los extractos etanólico, sus fracciones y sus fitofármacos en cápsulas de las hojas de Piper aduncum (matico) en dos modelos animales de experimentación.

\section{MATERIALES Y MÉTODOS}

Se realizó un estudio experimental, el cual tuvo dos partes: la evaluación del efecto gastroprotector en un experimental con ratones de la cepa Balb C57, y la evaluación del efecto gastrosecretor en un modelo experimental con ratas Holtzman. Para ello se empleó los extractos etanólico, sus fracciones y fitofármacos.

\section{RECOLECCIÓN DE LAS HOJAS, PREPARACIÓN DEL EXTRACTO Y FRACCIONES}

Las hojas se colectaron en la ciudad de La Merced (Junín, Perú), sobre los 800 metros de altitud. Previa limpieza, las hojas fueron estabilizadas, para ello, estas fueron colocadas en bolsas plásticas a las cuales se agregó gotas de alcohol metílico al $96^{\circ}$, para luego cerrar la bolsa y agitar su contenido; luego, las hojas fueron desecadas en estufa a $40^{\circ} \mathrm{C}$. La identificación taxonómica de las hojas se realizó tanto por comparación, en el Herbario San Marcos del Museo de Historia Natural de la Universidad Nacional Mayor de San Marcos, como por una consulta bibliográfica especializada (Trelease, W. \& T.G. Yuncker, 1950; Vásquez, R. 1997). Estos procesos permitieron determinar que las hojas recolectadas correspondían a Piper aduncum.

Para la preparación del extracto alcohólico se maceraron $100 \mathrm{~g}$ de hojas secas de matico, que luego fueron molidas en alcohol de $96^{\circ}$ (Etanol Fisher), se dejó reposar el preparado por 8 días, luego de los cuales se filtró el preparado y en seguida se evaporó el solvente en una estufa a $40^{\circ} \mathrm{C}$ hasta obtener un peso constante. El extracto etanólico de las hojas de Piper anduncum resultante $(30 \mathrm{~g})$ fue sometido a un proceso de partición por el método de cromatografía en columna rápida, para separar los diferentes componentes de las hojas. Para ello se sembró el extracto en una columna de sílicagel 
para cromatografía y se corrió, utilizando los solventes de menor a mayor polaridad: n-hexano (Fisher), cloroformo (Fisher), diclorometano (J.T. Baker) y metanol (Merck); los cuatro eluatos resultantes fueron secados a temperatura ambiente; recibieron los nombres de fracción n-hexano (rinde 1,8 g); fracción clorofórmica (rinde 1,6 g); fracción diclorometano (rinde 1,5 g), y fracción metanólica (rinde $13,3 \mathrm{~g}$ ). Con estas fracciones se realizaron la identificación de los grupos químicos siguiendo los procedimientos descritos por Lock ${ }^{(9)}$ y Domínguez ${ }^{(10)}$.

\section{PREPARACIÓN DEL FITOFÁRMACO EN CÁPSULAS}

Se prepararon cápsulas con la fracción metanólica de Piper aduncum (fitometanol) y cápsulas con extracto etanólico de Piper aduncum (fitoetanol). Se realizó el desarrollo de una formulación del fitofármaco en cápsulas, empleando lactosa anhidra, lauril sulfato de sodio y estearato de magnesio; de acuerdo a la buenas prácticas de manufactura con características físico químicas homogéneas y de alta solubilidad. El control de calidad microbiológico indicó para las cápsulas ausencia de Escherichia coli, Salmonella sp, Staphyloccocus aureus y Pseudomonas aeruginosa. El Instituto Quimioterápico (IQ Farma), se encargó de encapsular los extractos.

\section{EVALUACIÓN DE LA ACTIVIDAD GASTROPROTECTORA}

Se hizo la determinación de la actividad gastroprotectora en ratones, según O’Brien ${ }^{(11)}$, con modificación en la dosis de indometacina. Se utilizó 220 ratones machos de la cepa Balb C53, que tenían un peso de $28 \pm 3$ gramos, procedentes del Instituto Nacional de Salud. Los animales fueron aclimatados durante cinco días al ambiente de experimentación, se les mantuvo a una temperatura de $21^{\circ} \mathrm{C}$, con dieta y agua a libertad. Veinticuatro horas antes del ensayo se les sometió a ayuno, recibiendo agua a libertad.

Se dividió los animales en 22 grupos de diez animales cada uno, según se detalla a continuación. El grupo 1 o grupo normal (control negativo) recibió el vehículo que redisolvió las sustancias problemas (solución de polisorbato 80 al $3 \%$, a la dosis de $10 \mathrm{~mL} / \mathrm{kg}$ ). El grupo 2 o grupo indometacina $120 \mathrm{mg} / \mathrm{kg}$ (control positivo), como agente ulcerogénico, se preparó una suspensión de indometacina con polisorbato 80 al $3 \%$, para la administración se tuvo en cuenta agitar constantemente el volumen que contenian los miligramos necesarios según la dosis determinada, y la aplicación fue inmediata. Los grupos del 3 al 22 recibieron, además de indometacina (IND), las sustancias en investigación, según se detallan a continuación: los grupos del 3 al 6 recibieron IND + la fracción diclorometano (50, 150,
300 y 500 mg/kg, respectivamente); los grupos del 7 al 10 recibieron IND + la fracción n-hexano $(50,150,300$ y 500 $\mathrm{mg} / \mathrm{kg})$; a los grupos del 11 al 14 se les administró IND + la fracción clorofórmica (50, 150, 300 y 500 mg/kg); a los grupos del 15-18 se les dio IND + la fracción metanólica; y los grupos del 19 al 22 recibieron IND + el extracto etanólico $(50,150,300$ y $500 \mathrm{mg} / \mathrm{kg})$. Las fracciones y el extracto etanólico se reconstituyeron con polisorbato 80 solución al $3 \%$.

Para la administración se empleó una sonda metálica de acero inoxidable, se administró por vía oral el solvente y soluciones en las dosis indicadas; luego de 60 minutos se administró la indometacina por vía intraperitoneal, a todos los grupos, excepto al grupo normal; esto se repitió a las doce horas. Luego de seis horas de la última administración los animales fueron sacrificados, administrándoseles por vía intraperitoneal pentobarbital $100 \mathrm{mg} / \mathrm{kg}$. Mediante laparotomía se extrajo el estómago, que fue abierto por la curvatura mayor y se, observó la presencia de las lesiones.

La actividad gastroprotectora fue evaluada considerando tres indicadores: la inflamación, las bandas hemorrágicas y el número de úlceras. Los estómagos fueron conservados en una solución de formaldehido tamponado: formaldehido (Merck) 40\% (100 mL) + sodio fosfato monobásico monohidratado $(4 \mathrm{~g})+$ sodio fosfato dibásico anhidro $(6,5 \mathrm{~g})+$ agua destilada cantidad suficiente para un litro. La magnitud de la lesión observada en la mucosa gástrica (pérdida de continuidad o rotura) fue calificada según la escala de Alada modificada ${ }^{(12)}$ : normal = 0; leve (úlceras puntiformes $<1 \mathrm{~mm} \circ$ microhemorragias) $=1$; moderada (2 o más úlceras hemorrágicas pequeñas) $=2$; severa (úlceras grandes $>2 \mathrm{~mm}$ de diámetro) $=3$. El número de lesiones gástricas, por tratarse de una variable cuantitativa discreta, permitió determinar la eficacia del efecto gastroprotector (definida como el porcentaje de reducción de las lesiones) fue calculada según la fórmula: ((lesiones en grupo control negativo - lesiones en el grupo tratado) / lesiones en el grupo control negativo) $x$ 100. La inflamación fue evaluada según la magnitud del enrojecimiento presente siendo medida empleando la escala de puntaje observacional: ausente $=0$; leve $=1$; moderado $=2$; severo $=3$. La fórmula para determinar la eficacia del efecto gastroprotector (definida como el porcentaje de reducción de las lesiones) fue calculada como: ((lesiones en grupo control - lesiones en el grupo tratado) / lesiones en el grupo control) x 100.

\section{EVALUACIÓN DE LA ACTIVIDAD ANTISECRETORIA}

Para la determinación de la actividad antisecretoria se empleó el modelo experimental propuesto por Shay ${ }^{(13)}$, y las modificaciones propuestas por Long (14). Para ello se emplearon 64 ratas albinas (Holtzman). 
Los animales fueron separados al azar en ocho grupos de ocho animales cada uno. A todos los animales se les practicó un ligado pilórico (LP), las consideraciones en cada uno de los grupos se detalla a continuación. El grupo A fue el control negativo, y recibió únicamente el vehículo que redisolvió la sustancia problema (solución de polisorbato 80 al $3 \%$, dosis de $2 \mathrm{~mL} / \mathrm{kg}$ ); el grupo B, correspondió al control positivo, recibió ranitidina $100 \mathrm{mg} / \mathrm{kg}$; al grupo $\mathrm{C}$ se le administró el extracto etanólico $250 \mathrm{mg} / \mathrm{kg}$; el grupo D, el extracto metanólico $250 \mathrm{mg} / \mathrm{kg}$; el grupo E, fitoetanol (fitofármaco del extracto etanólico) $250 \mathrm{mg} / \mathrm{kg}$; el grupo E, fitoetanol $500 \mathrm{mg} / \mathrm{kg}$; el grupo F, fitometanol (fitofármaco del extracto metanólico) $250 \mathrm{mg} / \mathrm{kg}$; y el grupo G, fitometanol $500 \mathrm{mg} / \mathrm{kg}$.

Los animales fueron anestesiados con éter dietílico (Merck), se les hizo una laparotomía abdominal y se expuso el píloro, el cual fue ligado; seguidamente se administró las sustancias vía intraduodenal, se suturó el peritoneo por planos y, finalmente, a todos los animales se les administró histamina en dosis de 50 ug/kg por vía intraperitoneal. Luego de cuatro horas los animales fueron sacrificados por administración de pentobarbital $100 \mathrm{mg} / \mathrm{kg}$. Posteriormente, se extrajo los estómagos y se ligó el cardias, se midió el volumen de la secreción gástrica y se determinó su $\mathrm{pH}$, por medio de un potenciómetro ( $\mathrm{pH}$ Meter Metrohm modelo 691). Se determinó el porcentaje de inhibición de secreción (\% IS), teniendo en cuenta el volumen de secreción del control negativo (VSc) y el volumen de secreción de los compuestos evaluados (Vsp), según la siguiente fórmula: \% IS $=\{[(V S c-V S p) / V S c] 100\}$

La evaluación histopatológica se realizó siguiendo los lineamientos propuestos por Devi (15). Para ello, los estómagos fueron extirpados y lavados con solución salina para remover la sangre y los detritos adheridos al tejido. Luego fueron fijados en solución de formaldehido al 10\% tamponado, por 7 días. Posteriormente se seleccionó las zonas donde, de acuerdo al examen macroscópico, se evidenciaban las lesiones aparentes. Trascurrido este tiempo se les analizó en un procesador automático de tejido (Autotechnicon) por $18 \mathrm{~h}$, en soluciones de alcoholes para deshidratación, hidratación con xilol, y embebido en parafina. El procesamiento de los tacos de parafina se realizó empleando un dispensador de parafina. Los tacos obtenidos fueron llevados a congelamiento menor a $0{ }^{\circ} \mathrm{C}$, por un lapso de $3 \mathrm{~h}$, para luego proceder al corte de $3 \mu \mathrm{m}$ de espesor con ayuda de un micrótomo. Luego, se retiró la parafina en una estufa para proceder a la coloración con hematoxilina y eosina. Después de la deshidratación y limpieza, las láminas fueron llevadas para observación microscópica.

\section{ANÁLISIS DE DATOS}

Análisis del efecto gastroprotector. La evaluación de la actividad gastroprotectorase realizósobretres parámetros: inflamación, número de bandas hemorrágicas y número de úlceras. Para la comparación de estos parámetros se tuvieron las siguientes consideraciones. Se empleó la prueba de Kolmogorov-Smirnov (K-S) para evaluar la normalidad de las variables. Se determinó si existía relación entre el puntaje observacional y la dosis de los extractos a través de una razón de verosimilitud. Se determinó si existían diferencias significativas entre las medianas de las concentraciones dentro de cada extracto con las pruebas de Mann-Whitney y Kruskal-Wallis. Se determinó si existían diferencias significativas entre las medianas de la dosis del extracto y los controles positivo y negativo respectivamente.

Análisis del efecto antisecretorio. Para la descripción de las variables de interés se emplearon medidas de tendencia central (media \pm desviación estándar), además se estimaron, para los casos que así correspondiese, los intervalos de confianza al $95 \%$. Además, se estimaron los porcentajes de eficacia en cada grupo.

Para todas las pruebas estadísticas se fijó el nivel de significancia en 0,05 . Se empleó en todos los casos el software estadístico SPSS Ver. 13.0

\section{ASPECTOS ÉTICO}

El estudio contó con la aprobación del Comité de Investigación de la Facultad de Medicina de la Universidad Nacional Mayor de San Marcos. En cada uno de los procesos en los que estuviera incluido algún animal se cumplió con las buenas prácticas de manejo de animales de experimentación.

\section{RESULTADOS}

Ningún animal, ratón o rata fue excluido del experimento. En la Tabla 1 se presentan los metabolitos presentes en cada una de las fracciones evaluadas; en ella se puede apreciar que el extracto etanólico tiene principalmente compuestos fenólicos, flavonoides y alcaloides, la fracción metanólica contiene mayor cantidad de compuestos fenólicos y las fracciones clorofórmicas, metanólicas y etanólicas mayor cantidad de flavonoides.

\section{ACTIVIDAD GASTROPROTECTORA}

En la Tabla 2 se observa que los extractos de diclorometano, cloroformo, hexano y metanólico lograron una disminución de la inflamación producida 
Tabla 1. Compuestos presentes en el extracto etanólico de las hojas de Piper aduncum (matico) y sus fracciones (evaluación cualitativa, de acuerdo a reacción de color o precipitado)

\begin{tabular}{|c|c|c|c|c|c|c|}
\hline \multirow{2}{*}{$\begin{array}{c}\text { Grupo de } \\
\text { metabolito }\end{array}$} & \multirow{2}{*}{$\begin{array}{l}\text { Reactivo } \\
\text { utilizado }\end{array}$} & \multicolumn{5}{|c|}{ Fracciones } \\
\hline & & N-hexánico & Clorofórmico & Metanólico & Etanólico & Acuoso \\
\hline Fenólicos & Cloruro férrico & ++ & + & +++ & ++ & ++ \\
\hline Flavonoides & Shinoda & + & +++ & +++ & +++ & ++ \\
\hline Alcaloides & Dragendorff & - & ++ & ++ & ++ & + \\
\hline Saponinas & Espuma & - & + & + & + & + \\
\hline Esteroides & L. Burchard & - & - & + & + & - \\
\hline Quinonas & Bortranger & - & - & + & - & - \\
\hline Aceites & Olor & - & - & - & - & - \\
\hline Taninos & Gelatina & - & - & - & - & - \\
\hline Aminoácido & Ninhidrina & - & - & - & - & - \\
\hline
\end{tabular}

Nota. -: ausencia; +: poca cantidad; ++: regular cantidad; +++: abundante cantidad

por la indometacina en más del $66 \%$. Las concentraciones del extracto metanólico mostraron relación directa con la actividad antinflamatoria. Las concentraciones de los extractos de diclorometano y hexano tienen relación inversa con la actividad antinflamatoria. Las cuatro concentraciones $(50,150,300$ y $500 \mathrm{mg} / \mathrm{kg})$ de los extractos etanólicos mostraron la misma actividad antinflamatoria. Asimismo, se muestra que el extracto etanólico presenta una actividad de $100 \%$ para disminuir la gravedad de las lesiones gástricas y guarda relación directa entre dosis y actividad. Los extractos de diclorometano, hexano y cloroformo no presentan relación directa entre la dosis y la respuesta, sin embargo, algunas de las concentraciones presentan $100 \%$ de actividad para reducir la gravedad de las lesiones gástricas. Del mismo modo, se puede observar que el que el extracto clorofórmico presenta una actividad antiulcerosa de $75 \%$ y guarda relación directa entre las concentraciones de los extractos y actividad mostrada. La actividad antiulcerosa es semejante para las cuatro concentraciones del extracto

Tabla 2. Evaluación del efecto gastroprotector del por Piper aduncum (matico), en un modelo experimental de úlcera gástrica inducida por indometacina

\begin{tabular}{|c|c|c|c|c|c|c|c|c|c|c|c|c|c|}
\hline \multirow{2}{*}{ Grupo experimental * } & \multirow{2}{*}{$\begin{array}{c}\text { Dosis } \\
\text { (mg/kg) }\end{array}$} & \multicolumn{4}{|c|}{ Inflamación } & \multicolumn{4}{|c|}{ Bandas hemorrágicas } & \multicolumn{4}{|c|}{ Úlceras gástricas } \\
\hline & & $x \pm D E$ & $M_{\text {ed }}$ & p1 & p2 & $x \pm D E$ & $M_{\text {ed }}$ & p1 & p2 & $x \pm D E$ & $M_{e d}$ & p1 & p2 \\
\hline 1 (control negativo) & - & $1,4 \pm 0,5$ & 1 & $<0,01$ & --- & $0,3 \pm 0,7$ & 0 & $=0,01$ & -- & $0,3 \pm 0,9$ & 0 & $<0,01$ & --- \\
\hline 2 (control positivo) & - & $2,6 \pm 0,5$ & 3 & --- & 0,01 & $4 \pm 1,9$ & 3,5 & --- & $<0,01$ & $4,4 \pm 0,7$ & 4 & --- & $<0,01$ \\
\hline 3 (IND + diclorometa & 50 & $0 \pm 0,0$ & 1 & $<0,01$ & 14 & $0,0 \pm 0,0$ & 0 & $<0,01$ & 0,36 & $3,0 \pm 1,6$ & 3 & 0,07 & $=0,01$ \\
\hline & & $2 \pm 0,4$ & 1,5 & 0,01 & & & 0 & & & $, 5 \pm 2,4$ & 3 &, 05 & 0,01 \\
\hline 5 (IND + diclorometano) & & $1,5 \pm 0,5$ & 2 & $<0,01$ & ,66 & $0,7 \pm 0,8$ & 0,5 & $<0,03$ & 0,3 & $2,3 \pm 1,1$ & 2 &, 01 & $=0,01$ \\
\hline 6 (IND + & 500 & $, 7 \pm 0,7$ & 1 & 0,01 & ,31 & $0,9 \pm 0,9$ & 0,5 & $<0,04$ & 0,39 & $4,6 \pm 2,0$ & 5 & 0,88 & $<0,01$ \\
\hline & & $0 \pm 0,0$ & 1 & $<0,01$ & 14 & 0,0 & 0 & $<0,01$ & & $2,6 \pm 0,8$ & 3 &, 05 & $<0,01$ \\
\hline 8 (IND + N-Hexar & 50 & $1,3 \pm 0,5$ & 1,5 & $<0,01$ & 0,65 & $1,4 \pm 0,7$ & 1 & 0,02 & 0,06 & $4,2 \pm 2,9$ & 3,5 & 0,06 & $<0,02$ \\
\hline & & $, 7 \pm 0,8$ & 2 & 0,02 & & & 0 & & & 2,8 & 4,5 & 07 & $<0,03$ \\
\hline $10(\mathrm{I}$ & & $1,1 \pm$ & 1 & $<0,01$ & 13 &, 0 & 0 & $<0,01$ & 0 , & $2 \pm 1,6$ & 2,5 & ,08 & $<0,04$ \\
\hline 11 (IND + & & $1,4 \pm 0,5$ & 1 & $<0,01$ & 38 & $1,8 \pm$ & 2 & 0,09 & 0, & $4,9 \pm 1,5$ & 5 & 0,56 & $<0,01$ \\
\hline 12 (IND + & & $1,3 \pm 0,7$ & 1,5 & $<0,02$ &, 39 & 0,7 & 0 & $<0,01$ & 0 & $1,8 \pm 1,1$ & 1,5 & $<0,01$ & $<0,01$ \\
\hline 13 & & $1,4 \pm 0,5$ & 1 & $<0,03$ & 0,39 & $0,1 \pm$ & 0 & $<0,01$ & 0, & $1,5 \pm 1,1$ & 1,5 & $<0,01$ & 0,01 \\
\hline 14 (IND + & & $1,0 \pm 0,0$ & 1 & $<0,04$ & 0,39 & 0,7 & 0 & $<0,01$ & 0,99 & $0,9 \pm 1,1$ & 0,5 & $<0,01$ & 0,09 \\
\hline 15 (IND + metanólico) & & $1,7 \pm 0,7$ & 2 & 0,01 & 0,31 & $1,1 \pm 1,5$ & 0 & $<0,01$ & 0, & $1,7 \pm 1,6$ & 2 & $<0,01$ & 0,01 \\
\hline & & $1,6 \pm 0,7$ & 2 & $<0,01$ & 0,30 & $1,1 \pm 1,1$ & 1 & $<0,02$ & 0, & $1,4 \pm 1,1$ & 2 & $<0,02$ & 0,02 \\
\hline 17 (IND + metanólico) & 300 & $1,4 \pm 0,5$ & 1 & $<0,01$ & 0,99 & $0,8 \pm 0,9$ & 0,5 & $<0,03$ & 0,18 & $1,0 \pm 0,9$ & 1 & $<0,03$ & 0,03 \\
\hline 18 (IND + & 500 & $1,0 \pm 0,0$ & 1 & $<0,01$ & 0,14 & $0,3 \pm 0,7$ & 0 & $<0,04$ & 0,19 & $0,8 \pm 0,8$ & 1 & $<0,04$ & 0,04 \\
\hline 19 (IND + etanólico) & & $2,1 \pm 0,3$ & 2 & $<0,01$ & 0,04 & $2,4 \pm 1,6$ & 3 & 0,27 & $<0,01$ & $3,3 \pm 1,8$ & 2,5 & 0,13 & $<0,01$ \\
\hline 20 (IND + etanólico) & & $1,9 \pm 0,7$ & 2 & $<0,02$ & 0,04 & $1,6 \pm 1,2$ & 1,5 & 0,04 & 0,01 & $2,0 \pm 1,4$ & 2 & 0,01 & $<0,01$ \\
\hline & 300 & $1,8 \pm 0,6$ & 2 & $<0,03$ & 0,04 & $1,2 \pm 1,0$ & 1 & 0,01 & 0,03 & $1,8 \pm 0,6$ & 2 & $<0,01$ & $<0,01$ \\
\hline 22 (IND + etanólico) & 500 & $1,6 \pm 0,6$ & 2 & $<0,04$ & 0,04 & $0,8 \pm 1,8$ & 0 & $<0,01$ & 0,83 & $1,2 \pm 1,2$ & 1 & $<0,01$ & 0,04 \\
\hline
\end{tabular}

* Los datos de ninguno de los extractos presentó distribución normal ( $<<0,05$, Kolmogorov-Simirnov)

$\mathrm{X}$ : media; DE: desviación estándar; $\mathrm{M}_{\mathrm{ed}}$ : mediana; IND: indometacina, $\mathrm{p}_{1}$ : comparación entre las medianas de las dosis del extracto y de la indometacina

$80 \mathrm{mg} / \mathrm{kg}$, (Prueba de Mann-Whitney); $\mathrm{p}_{2}$ : comparación entre las medianas de las dosis del extracto y del suero fisiológico, (Prueba de Mann-Whitney) 
Tabla 3. Evaluación del efecto antisecretor del Piper aduncum (matico), en un modelo experimental de ligado pilórico

\begin{tabular}{|c|c|c|c|c|c|c|c|c|c|}
\hline \multirow{2}{*}{$\begin{array}{c}\text { Grupo experi- } \\
\text { mental } \\
(n=8)\end{array}$} & \multirow[b]{2}{*}{$\begin{array}{l}\text { Dosis } \\
\text { (mg/kg) }\end{array}$} & \multicolumn{4}{|c|}{ Volumen $(\mathrm{mL})$} & \multicolumn{4}{|c|}{$\mathrm{pH}$} \\
\hline & & Media & $\begin{array}{c}\text { Eficacia }^{\dagger} \\
(\%)\end{array}$ & DE & $\mathbf{p}^{*}$ & Media & Eficacia (\%) & DE & $\mathbf{p}^{*}$ \\
\hline A (control) & - & 8,3 & - & - & - & 1,4 & - & - & - \\
\hline B (ranitidina) & 100 & 4,2 & 49,7 & 0,7 & $<0,01$ & 3,4 & 139,0 & 0,3 & $<0,01$ \\
\hline C (etanol) & 250 & 2,1 & 74,7 & 0,5 & $<0,01$ & 2,6 & 82,6 & 0,2 & $<0,01$ \\
\hline D (metanol) & 250 & 3,3 & 60,6 & 0,5 & $<0,01$ & 2,6 & 82,6 & 0,2 & $<0,01$ \\
\hline$E$ (fitoetanol) & 250 & 2,3 & 72,0 & 0,6 & $<0,01$ & 2,9 & 104,3 & 0,3 & $<0,01$ \\
\hline F (fitoetanol) & 500 & 0,3 & 72,7 & 0,5 & $<0,01$ & 2,4 & 69,6 & 0,2 & 0,03 \\
\hline G (fitometanol) & 250 & 1,8 & 78,0 & 0,4 & $<0,01$ & 2,5 & 73,9 & 0,3 & 0,02 \\
\hline $\mathrm{H}$ (fitometanol) & 500 & 4,2 & 49,2 & 0,7 & $<0,01$ & 2,8 & 95,7 & 0,2 & $<0,01$ \\
\hline
\end{tabular}

DE: desviación estandar

* Análisis de varianza, utilizando comparación múltiple de Dunnett con respecto al control

† Porcentaje de eficacia $=(($ Control - tratamiento/Control $) \times 100)$

Etanol: extracto etanólico, metanol: fracción metanólica, fitoetanol: fitofármaco en cápsulas del extracto etanólico de matico fitometanol: fitofármaco en cápsulas de la fracción metanólica de matico

metanólico, cuya mediana ponderada es 1,5 (63\% de reducción en el número de úlceras).

\section{ACTIVIDAD ANTISECRETORA}

En la Tabla 3 se muestra que el porcentaje de eficacia antisecretora para los dos principales indicadores: el volumen, y el pH de la secreción gástrica. Todas las fracciones tuvieron un porcentaje de eficacia de reducción del volumen gástrico igual o superior al control positivo (ranitidina). Respecto al volumen todos los tratamientos fueron estadísticamente diferentes $(p<0,05)$ respecto de grupo control; solo el tratamiento con fitometanol $250 \mathrm{mg} / \mathrm{kg}$ fue estadísticamente diferente respecto al tratamiento ranitidina $100 \mathrm{mg} / \mathrm{kg}$ (control positivo). En relación al $\mathrm{pH}$, todos los tratamientos fueron estadísticamente diferentes $(p<0,05)$ respecto del grupo control; solo el tratamiento con fitoetanol $500 \mathrm{mg} / \mathrm{kg}$ fue estadísticamente diferente respecto al tratamiento ranitidina $100 \mathrm{mg} / \mathrm{kg}$ (control positivo).

\section{DISCUSIÓN}

El daño oxidativo es considerado por diferentes modelos experimentales y clínicos como un factor común en la patogénesis de la úlcera ${ }^{(16)}$. Los agentes antioxidantes al atrapar los radicales libres previenen la formación de la lesión ulcerogénica causada por estímulos estresantes, previniendo complicaciones mayores como el cáncer (17). Por otro lado, el Piper aduncum (matico) contiene flavonoides, saponinas, taninos, glucósidos, esteroides, alcaloides y muchos otros componentes químicos. Algunos de estos componentes bioactivos se han asociado con efectos gastroprotectores y antiulcerosos en estudios previos.
Es así que se ha descrito que los flavonoides poseen propiedades antioxidantes, además fortalecerían el sistema de defensa de la mucosa gástrica a través de la estimulación de la secreción de moco gástrico ${ }^{(18,19)}$, asimismo los taninos y alcaloides presentes en el extracto de dicha planta, estarían coadyuvando con dicho efecto farmacológico.

En estudios anteriores los compuestos flavonoides demostraron tener efecto antisecretor y propiedades citoprotectoras ${ }^{(20)}$, también se cree que aumentan la resistencia capilar y mejoran la microcirculación. Además, las hojas de la planta son también ricos en saponinas y taninos, sustancias respecto a los cuales se ha señalado que también presentarían propiedades antiulcerosas (21). En general, los taninos tienen efectos vasoconstrictores y precipitan las proteínas. Esta precipitación de proteínas formaría una película protectora impermeable sobre las úlceras que hace que a estas lesiones menos permeable a sustancias tóxicas y más resistente al ataque de enzimas proteolíticas ${ }^{(22)}$. Estos mecanismos explicarían el efecto gastroprotector de las hojas de Piper aduncum (matico); sin embargo, se requieren más estudios para aislar los componentes activos responsables de la actividad antiulcerosa, siendo esto una limitación del presente estudio.

Respecto al modelo experimental empleado para evaluar el efecto antisecretor, se puede acotar que el estrés inducido por la ligadura del píloro incrementa la producción de ácido y pepsina, los cuales, al encontrarse en mayor contacto con la mucosa gástrica, provocan la aparición de úlceras. Además, el ácido gástrico es un factor importante en la génesis de las úlceras en ratas con ligadura del píloro ${ }^{(9)}$. La activación del reflujo vago-vagal por la estimulación de la presión en los receptores de la mucosa del antro gástrico se 
estima que incrementa la hipersecreción de ácido gástrico en el modelo de ligadura del píloro ${ }^{(23)}$.

Un aspecto no estudiado en el presente trabajo, pero que ayudaría a comprender el efecto gastroportector de las hojas de matico es que los compuesto fenólicos como los flavonoides presentan una buena inhibición del Helicobacter pylori, y el efecto antibacteriano se debería a: (i) hiperacidificación en la interfase de la membrana plasmática de los microorganismos, o (ii) la acidificación intracelular, que resulta en la inhibición de la bomba $\mathrm{H}^{+} \mathrm{K}^{+}$ATP asa necesaria para la síntesis del ATP en las bacterias o (iii) puede estar relacionado con la inactivación de enzimas celulares que causan cambios en la permeabilidad de la membrana (24). Se requiere estudios adicionales para evaluar los extractos de Piper aduncum (matico) frente a Helicobacter pylori.

En la presente investigación se ha demostrado un efecto antisecretorio y gastroprotector al evaluar el extracto etanólico y metanólico de Piper aduncum (matico) así como sus respectivos fitofármacos en cápsulas, esta actividad parece estar presente también en otras especies del género Piper. Se ha demostrado el efecto cicatrizante del extracto etanólico de Piper angustifolium al ser usado en heridas inducidas a ratones ${ }^{(25)}$, así como un efecto protector al usar un jabón conteniendo extracto etanólico de hojas de la mencionada planta sobre piel sana de conejos ${ }^{(26)}$. Asimismo, se ha estudiado la actividad antiulcerosa de un flavonoide nuevo aislado 2"-0-ramnosil 4"-0-metil-vitexina de las hojas de Piper ossanum, mediante extracción con alcohol etílico al $70 \%$, la solución de flavonoides mostró una evidente actividad antiulcerosa expresada por el índice de lesión y el porcentaje de inhibición de formación de lesiones, por lo que se concluyó que ese flavonoide actuó como un antiulceroso similar al sucralfato ${ }^{(6)}$. Otro estudio estableció que el allylpyrocatechol (APC), el mayor constituyente de las hojas de Piper betel puede curar la úlcera estomacal en ratas por su acción antioxidante y la capacidad de formar mucosidad. Al parecer, por eliminación de los radicales libres, el APC podrían estar protegiendo la mucosa gástrica, y a su vez, el epitelio del estómago del daño del oxidativo. Esto acelera la curación de las úlceras gástricas. Anteriormente, nuestro grupo también ha informado la actividad citoprotectora del extracto etanólico crudo de las hojas de $P$. betel contra la ulceración del estómago inducida por indometacina. Estos resultados, tomados juntos con la no toxicidad del APC indican su potencial como una droga antiulcerogénica para otras investigaciones. La comparación de su eficacia con el de misoprostol llevó a confirmar los resultados ${ }^{(27)}$.

Es necesario señalar que el metanol y otros disolventes empleados en los modelos experimentales diseñados para el presente estudio son conocidos por su toxicidad. Estos fueron empleados para poder aislar la mayor cantidad de componentes activos de las hojas de matico. Por lo que, la aplicación industrial de estos extractos requiere la eliminación de estos disolventes antes de su uso en humanos.

Algunas limitaciones deben ser reconocidas. En primer lugar, para la evaluación de la actividad gastroprotectora se utilizó indometacina, como agente ulcerogénico, para lo cual se preparó como suspensión con polisorbato 80 al 3\%, hubiera sido ideal comparar el comportamiento de la indometacina como solución, disuelta en bicarbonato de sodio, la cual tiene mayor biodisponibilidad. Otra limitación fue que razones económicas no se pudo tener mayor cantidad de animales para probar un mayor número de dosis de los extractos utilizados.

En conclusión en condiciones experimentales los extractos etanólico, sus fracciones y su fitofármaco son gastroprotectores en ratones y antisecretores en ratas.

Agradecimientos: al Fondo para la Innovación, la Ciencia y la Tecnología (FINCyT) por el financiamiento, y al Instituto Quimioterápico (IQ Farma) por el encapsulamiento de los extractos de Piper adumcun.

Contribuciones de autoría: JA ha participado en la concepción y diseño del artículo, recolección, análisis e interpretación de datos, redacción y revisión del artículo. LME ha participado en el análisis, redacción, y revisión del artículo. $\mathrm{PB}, \mathrm{GR}, \mathrm{GT}, \mathrm{JH}, \mathrm{ER}$ y $\mathrm{MQ}$ han contribuido en la recolección, análisis y redacción del artículo. JRC ha participado en la asesoría estadística del artículo. Todos los autores aprobaron la versión final del artículo.

Fuentes de financiamiento: fondo para la Innovación, la Ciencia y la Tecnología (FINCyT).

Conflictos de interés: el Instituto Quimioterápico (IQ Farma), se encargó de encapsular los extractos, no participó en el análisis ni redacción del artículo, tampoco proporcionó incentivos económicos a los investigadores. Los autores declaran no tener conflictos de interés. 


\section{REFERENCIAS BIBLIOGRÁFICAS}

1. Cabrera FA, Herrera Manuel, Lorda L. Comportamiento de la úlcera gastroduodenal perforada. Rev Cub Med. 2011;40(1):12-21.

2. Lau J, Sung J, Hill C, Henderson C, Howden C, Metz D, et al. Systematic review of the epidemiology of complicated peptic ulcer disease: incidence, recurrence, risk factors and mortality. Digestion. 2011;84(2):10213. doi: $10.1159 / 000323958$.

3. Brack Egg A. Diccionario enciclopédico de plantas útiles del Perú. Cusco: Centro de Estudios Regionales Andinos "Bartolomé de las Casas"; 1999.

4. Luziatelli G, Sørensen M, Theilade I, Mølgaard P. Asháninka medicinal plants: a case study from the native community of Bajo Quimiriki, Junín, Peru.J Ethnobiol Ethnomed. 2010;6:21. doi: 10.1186/1746-4269-6-21.

5. Valadeau C, Castillo JA, Sauvain M, Lores AF, Bourdy G. The rainbow hurts my skin: medicinal concepts and plant uses among the Yanesha (Amuesha), an Amazonian Peruvian ethnic group. J Ethnopharmacol. 2010;127(1):175-92. doi: 10.1016/j.jep.2009.09.024.

6. Apecechea M, Larionova M, Salazar S, Abín G. Evaluación de la actividad antiulcerosa del 2"-0-ramnosil 4"-0-metil-vitexina de las hojas de Piper Ossanum. Rev Cubana Med Milit. 2000;29(2):114-7.

7. Quílez A, Berenguera B, Gilardoni G, Souccar C, De Mendonça S, Oliveirad LF, et al. Anti-secretory, antiinflammatory and anti-Helicobacter pylori activities of several fractions isolated from Piper carpunya Ruiz \& Pav. J Ethnopharmacol. 2010 Apr 21;128(3):583-9. doi: 10.1016/j. jep.2010.01.060.

8. Katzung B, Masters S, Trevor A. Farmacología Básica y Clínica. 11va edición. México: Mc Graw Hill Lange; 2009.

9. Lock O. Investigación Fitoquímica. 2 da edición. Lima: Fondo Editorial de la Pontificia Universidad Católica del Perú; 1994.
10. Domínguez J. Métodos de investigación fitoquímica. México: Editor Limusa Wiley; 1973.

11. O'Brien P, Frydman G, Holmes R, Malcontenti C, Phelan D. Evaluation of putative cytoprotective properties of antiulcer drugs using quantitative histological techniques. Dig Dis Sci. 1990;35(9):1130-9.

12. Alada ARA, Ajayi FF, Alaka OO, Akande OO. Gastric acid secretion and experimental ulceration in rats fed soybean diet preparations. African J Biomed Res. 2005;8(3):203-5.

13. Shay M, Komarov SA, Fels D, Meranze D, Guenstein H, Siplet H. A simple method for the uniform production of gastric ulceration in the rat. Gastroenterology. 1945;(5):43-61.

14. Long JF, Chiu PJ, Derelanko MJ, Steinberg M. Gastric antisecretory and cytoprotective activities of SCH 28080. J Pharmacol Exp Ther. 1983;226(1):114-20.

15. Devi RS, Narayan S, Vani G, Shyamala Devi CS. Gastroprotective effect of Terminalia arjuna bark on diclofenac sodium induced gastric ulcer. Chem Biol Interact. 2007;167(1):71-83.

16. Sairam K, Rao CV, Babu MO, Kumar KV, Agrawal VK, Goel RK Antiulcerogenic effect of methanolic extract of Emblica officinalis: an experimental study. J Ethnopharmacol. 2002;82(1):1-9.

17. Mizui T, Sato H, Hirose F, Doteuchi M. Effect of antiperoxidative drugs on gastric damage induced by ethanol in rats. Life Sci. 1987;41(6):755-63.

18. Gonzalez FG, Di Stasi LC. Antiulcerogenic and analgesic activities of the leaves of Wilbrandia ebracteata in mice. Phytomedicine, 2002;9(2):125-34.

19. Martin MJ, Marhuenda E, PerezGuerrero C, Franco JM. Antiulcer effect of naringin on gastric lesion induced by ethanol in rats. Pharmacology.1994;49(3):144-50.

20. Guaraldo L, Sertiè JA, Bacchi EM. Antiulcer action of the hydroalchoholic extract and fractions of Davilla rugosa
Poiret in rat. J Ethnopharmacol. 2001;76(2):191-5.

21. Lewis DA, Hanson PJ. Anti-ulcer drugs of plant origin. Prog Med Chem. 1991;28:201-31.

22. Nwafor PA, Okwuasaba FK, Binda LG. Antidiarrhoeal and antiulcerogenic effects of methanolic extracts of Asparagus pubescens root in rats. $\mathrm{J}$ Ethnopharmacol. 2000;72(3):421-7.

23. Baggio $\mathrm{CH}$, Freitas CS, Rieck L, Marques MC. Gastroprotective effects of a crude extract of Baccharis illinita DC in rats. Pharmacol Res. 2003;47(1):93-8

24. Arroyo J, Ráez E, Bonilla P. Efecto del jabón con Piper angustifolium $\mathrm{R}$ \& P (matico) sobre la piel normal en conejos. Folia Dermatológica Peruana. 2003;14(2):24-8.

25. Bhattacharya $S$, Banerjee D, Bauri AK, Chattopadhyay S, Bandyopadhyay SK. Healing property of the Piper betel phenol, allylpyrocatechol against indomethacin-induced stomach ulceration and mechanism of action. World J Gastroenterol. 2007;13(27):3705-13.

26. Vattem DA, Lin YT, Labbe RG, Shetty K. Phenolic antioxidant mobilization in cranberry pomace by solid-state bioprocessing using food grade fungus Lentinus edodes and effect on antimicrobial activity against selected food borne pathogens. Innov Food Sci Emerg. 2004:5(1):81-91.

27. Arroyo J, Pareja B, Ráez E. Efecto cicatrizante del Piper angustifolium $\mathrm{R}$ \& $\mathrm{P}$ sobre lesiones de piel inducidas en animales de experimentación. Folia Dermatológica Peruana. 1999;10(1):24-8

Correspondencia: Luis Moreno Exebio

Dirección: Centro Nacional de Control de Calidad, Instituto Nacional de Salud, Av. Defensores del Morro 2268, Lima 9, Perú.

Teléfono: 6176200 Anexo 1524

Correoelectrónico:lemoreno70@hotmail.com 